\title{
Management of Bile Duct Injuries: A 6-year Experience in a High Volume Referral Center
}

\author{
Simay Dal Çavuşoğlu ${ }^{1}$, Mutlu Doğanay ${ }^{2}$, Birkan Birben ${ }^{3}$, Gökhan Akkurt ${ }^{4}$, Özgur Akgul ${ }^{5}$, Mehmet Keşkek ${ }^{6}$
}

\begin{abstract}
Objectives: The aim of our study was to determine operative and nonoperative treatments performed in bile duct injuries and the effect of a multidisciplinary approach on the treatment.

Background: Bile duct injuries may lead to morbidities such as biliary leakage, peritonitis, and mortality.

Materials and methods: A total of 83 patients with biliary complications (37 patients with iatrogenic bile duct injury referred to our clinic from other centers were also included in this study) were evaluated.

Results: Of the operated 6,663 patients, iatrogenic bile duct injury occurred in $46(0.69 \%)$ of these patients. The most common type of injury was Strasberg type A injury, which was found in $48(57.83 \%)$ patients. The time interval between the diagnosis and initiation of treatment after the operation was shorter in patients with an inserted cavity drainage catheter $(p<0.05)$. Of the patients with bile duct injury, 32.6\% received surgical and $62.6 \%$ endoscopic treatment, while $4.8 \%$ were followed-up without intervention. The rate of mortality was found to be $2.4 \%$.

Conclusion: Time interval to diagnosis is of great importance for management of the patients.

Keywords: Bile duct, Cholecystectomy, Endoscopy.

Euroasian Journal of Hepato-Gastroenterology (2020): 10.5005/jp-journals-10018-1309
\end{abstract}

\section{INTRODUCTION}

Laparoscopic cholecystectomy (LC) has taken the place of open cholecystectomy $(\mathrm{OC})$ in the treatment management of gallstone diseases as the gold standard. ${ }^{1}$ Laparoscopic cholecystectomy provides superiority over $\mathrm{OC}$ with lower rates of morbidity and mortality. ${ }^{2}$ The rate of morbidity has been found as $1.9 \%$ with LC and $7.7 \%$ in OC, while the rate of mortality has been reported as $1 \%$ in LC and $5 \%$ in OC. ${ }^{3}$ Complications of bile duct injuries during LC are likely to be more proximal localized and more complicated such as the presence of accompanying vascular injury. ${ }^{4}$

latrogenic bile duct injuries are complications seen between $0.2 \%$ and $0.3 \%$ during $\mathrm{OC}^{5}$ whereas this percentage is slightly higher between $0.3 \%$ and $1.4 \%$ with LC. Biliary duct injuries may lead to morbidities such as biliary leak, peritonitis, and biliary stenosis and mortality. ${ }^{6}$ Approximately $20 \%$ of bile duct injuries are recognized during the operation. ${ }^{5}$ Studies have reported better outcomes in iatrogenic bile duct injuries followed up and treated in specialized hepatobiliary centers with a multidisciplinary approach. ${ }^{4,5}$

In this study, we aimed to determine operative and nonoperative treatments performed in bile duct injuries and the effect of a multidisciplinary approach on the treatment.

\section{Materials and Methods}

Patients who underwent LC operations at Ankara Numune Training and Research Hospital (ANTRH), General Surgery Clinic, between January 2010 and December 2016 were retrospectively reviewed. It was found that 6,663 operations were performed and 46 iatrogenic bile duct injuries occurred during this period. An additional 37 patients referred to our clinic from other centers with iatrogenic bile duct injury after LC operation was also included in the study.

\begin{abstract}
${ }^{1}$ Department of General Surgery, Mağusa Live Hospital, Cyprus
${ }^{2-6}$ Department of General Surgery, Numune Training and Research Hospital, Ankara, Turkey

Address reprint requests to: Gökhan Akkurt, Department of General Surgery, Numune Training and Research Hospital, Ankara, Turkey, Phone: +90 3123569000, e-mail: drakkurt06@gmail.com

How to cite this article: Çavuşoğlu SD, Doğanay $M$, Birben $B$, et al. Management of Bile Duct Injuries: A 6-year Experience in a High Volume Referral Center. Euroasian J Hepato-Gastroenterol 2020;10(1):22-26.

Source of support: Nil

Conflict of interest: None
\end{abstract}

Thus, a total of 83 patients with bile duct injury, followed up and treated in our clinic, were included in the study. Ethics committee approval was received before beginning this retrospective observational study (Decision no: E-17-1459).

All patients with iatrogenic bile duct injury underwent LC operation with the four-trocar technique. Patients' age, gender, a history of previous acute cholecystitis, jaundice/pancreatitis, previous abdominal operation, obesity, and comorbidities as well as preoperative laboratory and ultrasonography findings, a history of endoscopic retrograde cholangiopancreatography $(E R C P)$, status of undergoing intraoperative cholangiography, drain insertion, previous emergency or elective surgery, time of the operation (day/night), and complaints of admission after the operation were recorded. Patients were examined in two groups as the patients operated in our clinic and those operated in an outer center. Classification of bile duct injuries was made using the Strasberg classification. ${ }^{7}$ Treatments administered, outcomes of the treatments, and the need for a second treatment were recorded.

(c) The Author(s). 2020 Open Access This article is distributed under the terms of the Creative Commons Attribution 4.0 International License (https://creativecommons. org/licenses/by-nc/4.0/), which permits unrestricted use, distribution, and non-commercial reproduction in any medium, provided you give appropriate credit to the original author(s) and the source, provide a link to the Creative Commons license, and indicate if changes were made. The Creative Commons Public Domain Dedication waiver (http://creativecommons.org/publicdomain/zero/1.0/) applies to the data made available in this article, unless otherwise stated. 


\section{Statistics}

The Mann-Whitney $U$ test was used in the comparisons of time to present to the hospital after operation according to the status of drain insertion.

\section{Results}

Of the operated 6,663 patients at ANTRH, 4,831 were female and 1,832 were male. latrogenic bile duct injury was found in $46(0.69 \%)$ of these patients. A total of 83 bile duct injuries were evaluated, which included 37 patients referred from other centers. The mean age of patients was 51.10 years (20-81). Age and gender distribution of the 83 patients is given in Table 1 .

Of the 83 patients, 38 had a history of previous acute cholecystitis, 4 acute biliary pancreatitis, 7 acute cholangitis, 16 previous abdominal operation, 1 obesity, and 30 patients had comorbidities mostly being diabetes and hypertension. Multiple millimetric stones, biliary sludge, and stones larger than $1 \mathrm{~cm}$ in the gallbladder were found on the preoperative ultrasonography. Biliary ducts were normal in 72 patients, intrahepatic bile ducts were dilated in 3 patients, and both intra- and extrahepatic bile ducts were dilated in 4 patients. Choledochal sludge was found in one patient, and choledochal dilatation in three patients. Four (4.82\%) of all patients with bile duct injury had a history of ERCP and these patients were operated in our clinic. Of the patients, 69 underwent elective and 14 emergency surgery. Of the 14 patients who underwent emergency surgery, 13 were operated during the day and 1 patient at night. Twelve (26.09\%) of the injury cases were recognized during the operation in our clinic. Postoperative complaints of the patients included bile leakage from the drain in 41 (49.4\%), abdominal pain in 23 (27.7\%), bile leakage from the incision site in 4 (4.8\%), and jaundice in 4 (4.8\%). No active complaint was found and no bile duct injury was detected in 11 (13.3\%) patients in the outpatient clinic follow-up after operation. In our study, a cavity drain was inserted in 57 (68.7\%) patients. It was found that durations to diagnosis and initiation of the treatment after the operation were shorter in patients with cavity drainage inserted, and the difference was statistically significant $(p<0.05)$. A cavity drain was inserted in 42 patients operated in our clinic. It was found that four of the patients with a cavity drain underwent cholangiography due to suspected bile duct injury. The cavity drain was inserted during surgery in 15 of the 37 patients referred from other centers. Types of injuries were determined in the patients based on the Strasberg classification. Distribution of the types of injury is given in Table 2. Endoscopic and surgical treatment was examined according to the types of injury. The followed and treated bile duct injuries are shown in Table 3.

All of the 48 type A bile duct injuries were successfully treated as a result of the treatments applied. Strasberg type B injury was seen in one (1.20\%) patient during the operation and it was found that the right aberrant hepatic duct was ligated. Roux-en-Y hepaticojejunostomy (RYHJ) was performed in this patient since the hepatic duct was wide ( $>3 \mathrm{~mm}$ ). Strasberg type $C$ injury was found in eight $(9.6 \%)$ patients. Six patients were stented, while a nasobiliary catheter was inserted in one patient. The remaining one patient presented to the emergency department with acute abdomen, underwent laparotomy, the open duct was ligated, and choledochal T-tube drainage was performed. Strasberg type D injury was observed in 11 (13.3\%) patients. Four cases were recognized during the operation and primary repair and T-tube insertion were carried out in the choledoch. Four patients presented with acute abdomen manifestation in the postoperative period, underwent laparotomy, primary repair, and T-tube insertion in the choledoch. The other three patients underwent stenting. Strasberg

Table 1: Age and gender distribution of the patients

\begin{tabular}{|c|c|c|c|c|c|c|}
\hline & \multicolumn{2}{|c|}{$\operatorname{ANTRH}(n=46)$} & \multicolumn{2}{|c|}{ Outer center $(n=37)$} & \multicolumn{2}{|c|}{ Total } \\
\hline & $n$ & (\%) & $n$ & (\%) & $n$ & (\%) \\
\hline \multicolumn{7}{|l|}{ Age group } \\
\hline$\leq 65$ years old & 36 & 78.26 & 30 & 81.08 & 66 & 79.52 \\
\hline$>65$ years old & 10 & 21.74 & 7 & 18.92 & 17 & 20.48 \\
\hline \multicolumn{7}{|l|}{ Gender } \\
\hline Female & 31 & 67.39 & 32 & 86.49 & 63 & 75.90 \\
\hline Male & 15 & 32.61 & 5 & 13.51 & 20 & 24.10 \\
\hline
\end{tabular}

Table 2: Distribution of the types of injuries

\begin{tabular}{|c|c|c|c|c|c|c|}
\hline & \multicolumn{2}{|c|}{$\operatorname{ANTRH}(n=46)$} & \multicolumn{2}{|c|}{ Outer center $(n=37)$} & \multicolumn{2}{|c|}{ Total } \\
\hline & $n$ & (\%) & $n$ & (\%) & $n$ & (\%) \\
\hline Type of injury & 46 & & 37 & & 83 & \\
\hline Strasberg A & 28 & 60.87 & 20 & 54.05 & 48 & 57.83 \\
\hline Strasberg B & 1 & 2.17 & 0 & 0.00 & 1 & 1.20 \\
\hline Strasberg C & 4 & 8.70 & 4 & 10.81 & 8 & 9.64 \\
\hline Strasberg D & 6 & 13.04 & 5 & 13.51 & 11 & 13.25 \\
\hline Strasberg E1 & 3 & 6.52 & 2 & 5.41 & 5 & 6.02 \\
\hline Strasberg E2 & 4 & 8.70 & 3 & 8.11 & 7 & 8.43 \\
\hline Strasberg E3 & 0 & 0.00 & 2 & 5.41 & 2 & 2.41 \\
\hline Strasberg E4 & 0 & 0.00 & 1 & 2.70 & 1 & 1.20 \\
\hline
\end{tabular}


Table 3: Bile duct injuries followed up and treated at ANTRH

\begin{tabular}{|c|c|c|c|c|c|c|c|c|c|}
\hline $\begin{array}{l}\text { Type of } \\
\text { injury }\end{array}$ & ANTRH (\%) & $\begin{array}{l}\text { Preoperative } \\
\text { diagnosis }\end{array}$ & $\begin{array}{l}\text { Postoperative } \\
\text { diagnosis }\end{array}$ & $\begin{array}{l}\text { Outer center } \\
(\%)\end{array}$ & Total (\%) & $\begin{array}{l}\text { Medical } \\
\text { treatment } \\
\text { (\%) }\end{array}$ & $\begin{array}{l}\text { Endoscopic } \\
\text { treatment } \\
\text { (\%) }\end{array}$ & $\begin{array}{l}\text { Surgical } \\
\text { treatment } \\
\text { (\%) }\end{array}$ & Total (\%) \\
\hline$A$ & $28(60.8)$ & 2 & 26 & $20(54)$ & $48(57.8)$ & $4(4.8)$ & $42(50.6)$ & $2(2.4)$ & $48(57.8)$ \\
\hline B & $1(2.2)$ & 1 & - & - & $1(1.2)$ & - & - & $1(1.2)$ & $1(1.2)$ \\
\hline C & $4(8.8)$ & - & 4 & $4(10.8)$ & $8(9.6)$ & - & $7(8.4)$ & $1(2.4)$ & $8(9.6)$ \\
\hline D & $6(13)$ & 4 & 2 & $5(13.5)$ & $11(13.3)$ & - & $3(3.6)$ & $8(9.6)$ & $11(13.3)$ \\
\hline E1 & $3(6.5)$ & 2 & 1 & $2(5.4)$ & $5(6.1)$ & - & - & $5(6)$ & $5(6.1)$ \\
\hline E2 & $4(8.7)$ & 3 & 1 & $3(8.1)$ & $7(8.4)$ & - & - & $7(8.4)$ & $7(8.4)$ \\
\hline E3 & - & - & - & $2(5.4)$ & $2(2.4)$ & - & - & $2(2.4)$ & $2(2.4)$ \\
\hline E4 & - & - & - & $1(2.7)$ & $1(1.2)$ & - & - & $1(1.2)$ & $1(1.2)$ \\
\hline E5 & - & - & - & - & - & - & - & - & - \\
\hline Total & $46(100)$ & $12(26)$ & $34(74)$ & 37 (100) & $83(100)$ & $4(4.8)$ & $52(62.6)$ & $27(32.6)$ & $83(100)$ \\
\hline
\end{tabular}

ANTRH, Ankara Numune Training and Research Hospital

Table 4: Progression of iatrogenic bile duct injuries followed up and treated in the ANTRH General Surgery Clinic

\begin{tabular}{|c|c|c|c|c|c|c|c|c|c|}
\hline $\begin{array}{l}\text { Type of } \\
\text { injury }\end{array}$ & $\begin{array}{l}\text { Number of } \\
\text { injuries }\end{array}$ & Recovery & $\begin{array}{l}\text { Need for } \\
\text { second } \\
\text { treatment }\end{array}$ & $\begin{array}{l}\text { Interventional } \\
\text { radiology }\end{array}$ & $\begin{array}{l}\text { Endoscopic } \\
\text { treatment }\end{array}$ & $\begin{array}{l}\text { Surgical } \\
\text { treatment }\end{array}$ & Recovery & $\begin{array}{l}\text { Jaundice } \\
\text { attacks }\end{array}$ & Exitus \\
\hline A & 48 & 42 & 6 & 3 & 2 & 1 & 6 & - & - \\
\hline B & 1 & 1 & - & - & - & - & - & - & - \\
\hline C & 8 & 6 & 2 & 2 & - & 2 & 1 & - & 1 \\
\hline D & 11 & 5 & 6 & - & 4 & 2 & 4 & 1 & 1 \\
\hline E1 & 5 & 4 & 1 & - & 1 & - & 1 & - & - \\
\hline E2 & 7 & 6 & 1 & 1 & - & - & 1 & - & - \\
\hline E3 & 2 & 1 & 1 & - & - & 1 & 1 & - & - \\
\hline E4 & 1 & 1 & - & - & - & - & - & - & - \\
\hline E5 & - & - & - & - & - & - & - & - & - \\
\hline Total & 83 (100\%) & 66 (79.5\%) & 17 (20.5\%) & 6 & 7 & 6 & 14 (16.8\%) & $1(1.2 \%)$ & $2(2.4 \%)$ \\
\hline
\end{tabular}

ANTRH, Ankara Numune Training and Research Hospital

type E1 injury was found in five (6.1\%) patients. Two of them were recognized during the operation. Four patients underwent Rouxen-Y hepaticojejunostomy, and one patient end-to-end anastomosis plus T-tube insertion. Strasberg type E2 injury was found in seven (8.4\%) patients with three were recognized during the operation. Six patients underwent Roux-en-Y hepaticojejunostomy, and one patient end-to-end anastomosis plus T-tube insertion. Strasberg type E3 injury was found in two patients, and both of them underwent Roux-en-Y hepaticojejunostomy. Strasberg type E4 injury was seen in one patient, and continuity of the both hepatic ducts was provided with Roux-en-Y hepaticojejunostomy. Progression of iatrogenic bile duct injuries is given in Table 4.

\section{Discussion}

Bile duct injuries occurring during LC are seen in $0.33-1.4 \%$ of cases. $^{5,6,8}$ In Turkey, $90 \%$ of 200,000 cholecystectomy surgeries performed yearly are done laparoscopically. Given these figures and injury rates, management of the treatment is of importance. ${ }^{9}$ The rate of injury was found to be $0.69 \%$ in our center, and is within the limits reported in the literature. ${ }^{5,6,8}$ Local risk factors are seen in $15-35 \%$ of bile duct injuries. In our study, a history of previous cholecystitis was found in 65\%, and history of cholangitis and acute biliary pancreatitis in $35 \%$ of the patients. Of the operated patients, $10(21.7 \%)$ had acute cholecystitis, 2 (4.3\%) acute biliary pancreatitis, and $1(2.1 \%)$ obesity. Considering the rates of local risk factors reported in the literature, the presence of local risk factors found as $28.1 \%$ in our study was within the limits stated in the literature. ${ }^{4}$ The rate of detecting bile duct injuries during $\mathrm{LC}$ operation varies between $11 \%$ and $23 \% .^{2,10}$ In our clinic, 12 (26.09\%) of the cases were recognized during the operation. Patients with bile duct injury usually show earlier postoperative findings in cases of biliary leakage compared to stenosis. ${ }^{2}$ The presence of a cavity drain is of paramount importance in providing biliary drainage and in the prevention of sepsis. ${ }^{11}$ When patients were evaluated according to the cavity drain status, it was found that timing of bile duct injury detection and initiation of treatment was shorter in the patients with a cavity drain inserted when compared to those without a cavity drain. Based on this result obtained in our study, cavity drain insertion is recommended, because this will significantly shorten time to diagnosis and initiation of the treatment especially in bile duct injuries that progress with biliary leakage in the cases where the stages described in safe cholecystectomy cannot be applied due to various reasons.

The Strasberg classification was used in our study for classification of bile duct injuries, because it is a classification involving all injuries including biliary leakage, it can be readily used in multidisciplinary treatment management in clinical practice, and due to its advantages of facilitating comparison between different centers. The multidisciplinary approach is of paramount importance 
both in the diagnosis and determination of treatment methods in iatrogenic bile duct injuries. ${ }^{10,12}$ In our clinic, endoscopic methods were applied in 52 (62.6\%) patients as the initiation therapy. As is seen, endoscopic methods are primarily preferred in eligible patients. Strasberg type A injuries are biliary leakages seen from a minor duct, with continuing association with bile ducts. These are biliary leakages usually resulting from cystic stump due to the failure of appropriate clipping of the cystic duct or from an injury to a peripheral hepatic duct (Luschka), which ends in the liver bed. ${ }^{7}$ Endoscopic treatment in which bile duct pressures obtained by the sphincter of Oddi are decreased with sphincterotomy and nasobiliary catheter or stent has almost completely eliminated the need for surgery in these injuries. ${ }^{5}$ Endoscopic treatment has a success rate between $66 \%$ and $100 \%$ in major bile duct-related injuries, especially in type $A$ injuries and type $D$ injuries where injury area is not wide. ${ }^{10}$ Type A injury was detected in 48 of our patients. Two of them were preoperatively identified and treated surgically, 4 of the remaining 46 patients were spontaneously recovered in maximum 4 days at follow-up, while 42 injuries were treated with the endoscopic technique. Whereas recovery was observed by $87.5 \%$ after the initial treatments, six patients required a second treatment, but recovery by $100 \%$ was seen in type A bile duct injuries after the subsequent treatments.

Strasberg type B injuries are the injuries with an occlusion occurring with ligation and cut of the right aberrant duct. If these injuries are not recognized during surgery, they usually cannot be detected in the postoperative period because of their asymptomatic course. Even symptomatic, prolonged, and repeating cholangitis attacks are extremely rare in these patients. In our study, type B injury was found in one (2.1\%) patient during the operation. This patient underwent Roux-en-Y hepaticojejunostomy, since the bile duct was $>3 \mathrm{~mm}$. A bile duct injury $<3 \mathrm{~mm}$ in width can be ligated, but injuries $>3 \mathrm{~mm}$ must be definitely repaired. A duct of this width can drain more than one hepatic segment, and in the case of ligation some complications may be seen including repeating cholangitis attacks and liver abscess. ${ }^{13}$ Strasberg type $C$ injuries are the injuries with biliary leakage occurring due to transection of the right aberrant duct without occlusion. This type of injury may cause local intraperitoneal bile collections, biliary acid, and peritonitis, and almost always require treatment. ${ }^{14}$ In the case of injury of an isolated bile duct that is not connected to the major bile ducts or aberrant bile duct, endoscopic identification and treatment of these injuries are more challenging. In such case, surgical treatment should be preferred in cases of failed endoscopic treatment or as the first choice. ${ }^{10,15}$ Type $C$ injury was detected in eight of our patients. Four of these injuries occurred at ANTRH and all type $C$ injuries were recognized during the operation. Seven patients underwent endoscopic and one patient surgical treatment. One patient initially underwent endoscopic treatment and then required additional treatment and the patient died from repeating cholangitis attacks and eventually from sepsis due to cholangitis at follow-up. It should be kept in mind that the clinical picture may worsen within days and sepsis may occur in patients with bile duct injury. ${ }^{16}$ Strasberg type $D$ injuries are the injuries in which major bile ducts are partially transected $(<50 \%)$ and they often can be treated with decompression through sphincterotomy in the postoperative period. Sphincterotomy and bypassing the area of leakage with a stent are the recommended treatment methods in leakages from the major ducts. The most important late complication in these injuries are the development of stenosis secondary to biliary leakage. ${ }^{10}$
In our clinic, 11 type D injuries were followed up and treated. Eight patients underwent primary choledoc repair and T-tube insertion. Intraoperative cholangiography is crucial in the injuries requiring surgical treatment, and a success rate has been reported as $85 \%$ in surgical repair of major bile duct injury in an experienced center where biliary tree is completely viewed. ${ }^{1,17}$ The remaining three patients with type $D$ injury underwent sphincterotomy plus stenting. A total of 9 of 11 patients followed up and treated in our clinic recovered following the first and second treatments (81\%). This rate was consisted within the recovery rates reported in the literature. One patient received endoscopic treatment in an other center due to cholangitis attack at follow-up and continued treatment at this center. One patient with type D injury died from sepsis during the treatment. Total rate of mortality was $2.4 \%$. The rates of mortalities in bile duct injuries have been reported in the literature between 0 and 3\% and our rate of mortality was within the range in the literature. Strasberg type E injuries (1-5) are the injuries occurring with complete incision of the major bile ducts. Type $E$ injuries define separation of the parenchyma from the lower bile ducts due to stenosis, occlusion, or transection. Treatment of type $\mathrm{E}$ injury is surgical. ${ }^{10}$ Ideal treatment in complete incision of the major bile ducts is to provide bilioenteric continuity with Roux-en-Y hepaticojejunostomy. Of the 15 patients with Strasberg type E injury, 13 underwent Roux-en-Y hepaticojejunostomy and 2 end-to-end anastomosis plus T-tube drainage. In a study from Amsterdam, a total of 56 bile duct injuries were treated with endto-end anastomosis ( 49 with T-tube). These patients were followed with endoscopic and radiologic intervention, when deemed necessary, and stenosis was found in more than $90 \%$ of the cases during a 7 -year follow-up. ${ }^{18}$ A success rate of $84 \%$ was achieved in the surgical treatment of bile duct injuries that are followed and treated in a center with an experienced hepatobiliary surgeon, an endoscopist, and a radiologist with complete visualization of the biliary tree. The success rate was $92.3 \%$ in 26 injuries operated in our clinic, higher than reported in the literature. This might be explained by the fact that long-term follow-up of patients in the postoperative period could not be performed. As known, biliary duct stenosis may develop after months even years, rate of biliary stenosis cannot be predicted in patients undergoing surgical treatment. Therefore, our success rate was significantly higher than in the literature.

\section{Conclusion}

The multidisciplinary approach is of paramount importance both in diagnosis and treatment of iatrogenic bile duct injuries. Besides an experienced team, time to diagnosis and initiation of the treatment are crucial in success of the treatment. Based on our results, we recommend cavity drain insertion in LC cases where safe cholecystectomy conditions cannot be provided, since it will significantly shorten time to the diagnosis and initiation of the treatment.

\section{References}

1. Al-Kubati WR. Bile duct injuries following laparoscopic cholecystectomy: a clinical study. Saudi J Gastroenterol 2010;16(2):100. DOI: 10.4103/1319-3767.61236.

2. Karanikas M, Bozali F, Vamvakerou V, et al. Biliary tract injuries after lap cholecystectomy - types, surgical intervention and timing. Ann Transl Med 2016;4(9):163. DOI: 10.21037/atm.2016.05.07.

3. Duca S, Bãlã O, Al-Hajjar N, et al. Laparoscopic cholecystectomy: incidents and complications. A retrospective analysis of 9542 
consecutive laparoscopic operations. HPB Surg 2003;5(3):152-158. DOI: 10.1080/13651820310015293.

4. Machado NO. Biliary complications post laparoscopic cholecystectomy: mechanism, preventive measures, and approach to management: a review. Diagn Ther Endosc 2011;2011:967017. DOI: 10.1155/2011/967017.

5. Salama IA, Shoreem HA, Saleh SM, et al. latrogenic biliary injuries: multidisciplinary management in a major tertiary referral center HPB Surg 2014;2014::575136. DOI: 10.1155/2014/575136.

6. Abbasoglu O, Tekant $Y$, Alper A, et al. Prevention and acute management of biliary injuries during laparoscopic cholecystectomy: expert consensus statement. Ulus Cerrahi Derg 2016;32(4):300-305. DOI: 10.5152/UCD.2016.3683.

7. Strasberg SM. Laparoscopic biliary injuries. diseases of the gallbladder and bile ducts: diagnosis and treatment. HPB Surg 2008. 182.

8. Brunicardi F, Andersen D, Billiar T, et al. Schwartz's Principles of Surgery. New York: McGraw-Hill Professional; 2004.

9. Basara BB, Guler C, Yentur G, The Ministry of Health of Turkey health statistics yearbook 2012. General Directorate of Health Research, Republic of Turkey Ministry of Health 2013.

10. Rauws E, Gouma D. Endoscopic and surgical management of bile duct injury after laparoscopic cholecystectomy. Best Practice \& Research 2004;18(5):829-846. DOI: 10.1016/j.bpg.2004.05.003.

11. Jarnagin WR, Blumgart L. Blumgart's surgery of the liver, biliary tract, and pancreas. Elsevier Saunders; 2012.
12. Csendes A, Navarrete C, Burdiles $P$, et al. Treatment of common bile duct injuries during laparoscopic cholecystectomy: endoscopic and surgical management. World J Surg 2001;25(10):1346-1351. DOI: 10.1007/s00268-001-0121-5.

13. Massarweh NN, Devlin A, Symons RG, et al. Risk tolerance and bile duct injury: surgeon characteristics, risk-taking preference, and common bile duct injuries. J Am Coll Surg 2009;209(1):17-24. DOI: 10.1016/j.jamcollsurg.2009.02.063.

14. Pucher PH, Brunt LM, Fanelli RD, et al. SAGES expert Delphi consensus: critical factors for safe surgical practice in laparoscopic cholecystectomy. Surg Endosc 2015;29(11):3074-3085. DOI: 10.1007/ s00464-015-4079-z.

15. Sicklick JK, Camp MS, Lillemoe KD, et al. Surgical management of bile duct injuries sustained during laparoscopic cholecystectomy: perioperative results in 200 patients. Ann Surg 2005;241(5):786. DOI: 10.1097/01.sla.0000161029.27410.71.

16. Stewart L. latrogenic biliary injuries: identification, classification, and management. Surgical Clinics 2014;94(2):297-310. DOI: 10.1016/ j.suc.2014.01.008.

17. Kapoor VK. Management of bile duct injuries: a practical approach. Am Surg 2009;75(12):1157-1160.

18. De Reuver PR, Busch ORC, Rauws EA, et al. Long-term results of a primary end-to-end anastomosis in peroperative detected bile duct injury. J Gastrointest Surg 2007;11(3):296-302. DOI: 10.1007/s11605007-0087-1. 